BMJ Open

Diabetes

Research

\& Care

\title{
Cerebral small-vessel disease is associated with the severity of diabetic retinopathy in type 1 diabetes
}

Marika I Eriksson (10 , ${ }^{1,2,3}$ Paula Summanen, ${ }^{1,3,4}$ Daniel Gordin, ${ }^{1,2,3,5}$

Carol Forsblom, ${ }^{1,2,3}$ Sara Shams, ${ }^{6,7}$ Ron Liebkind, ${ }^{8}$ Turgut Tatlisumak, ${ }^{8,9}$ Jukka Putaala, ${ }^{8}$ Per-Henrik Groop, ${ }^{1,2,3,10}$ Juha Martola, ${ }^{6,11}$ Lena M Thorn, ${ }^{1,2,3,12}$ on behalf of the FinnDiane Study Group

To cite: Eriksson MI, Summanen P, Gordin D, et al. Cerebral small-vessel disease is associated with the severity of diabetic retinopathy in type 1 diabetes. BMJ Open Diab Res Care 2021;9:e002274. doi:10.1136/ bmjdrc-2021-002274

Received 15 March 2021 Accepted 19 July 2021

Check for updates

C Author(s) (or their employer(s)) 2021. Re-use permitted under CC BY-NC. No commercial re-use. See rights and permissions. Published by BMJ.

For numbered affiliations see end of article.

\section{Correspondence to} Professor Per-Henrik Groop; per-henrik.groop@helsinki.fi

\section{ABSTRACT}

Introduction Cerebral small-vessel disease is common in neurologically asymptomatic individuals with type 1 diabetes. The retinal vasculature is thought to mirror the brain's vasculature, but data on this association are limited in type 1 diabetes. Our aim was to study associations between diabetic retinopathy severity and cerebral smallvessel disease in type 1 diabetes.

Research design and methods For this cross-sectional study, we enrolled 189 participants with type 1 diabetes (median age 40 (33-45) years; 53\% female; diabetes duration 21.6 (18.2-30.7) years) and 29 healthy agematched and sex-matched controls as part of the Finnish Diabetic Nephropathy Study. Participants underwent a clinical investigation, brain MRI, and fundus imaging. Signs of cerebral small-vessel disease in brain MRIs were analyzed in relation to diabetic retinopathy severity (Early Treatment Diabetic Retinopathy Study (ETDRS) score). Results In type 1 diabetes, participants with cerebral small-vessel disease had higher ETDRS scores (35 (20-61) vs 20 (20-35), $p=0.022$ ) and a higher prevalence of proliferative diabetic retinopathy than those without cerebral small-vessel disease ( $25 \%$ vs $9 \%, p=0.002$ ). In adjusted analysis, proliferative diabetic retinopathy was associated with cerebral small-vessel disease (OR 2.57 (95\% Cl 1.04 to 6.35)). Median ETDRS score (35 (20-65) vs 20 (20-35), $\mathrm{p}=0.024)$ and proliferative diabetic retinopathy prevalence were higher ( $29 \%$ vs $13 \%$, $p=0.002$ ) in participants with versus without cerebral microbleeds. ETDRS scores increased by number of cerebral microbleeds $(p=0.001)$, both ETDRS score (OR 1.05 (95\% $\mathrm{Cl} 1.02$ to 1.09)) and proliferative diabetic retinopathy (8.52 (95\% Cl 1.91 to 37.94$))$ were associated with $>2$ cerebral microbleeds in separate multivariable analysis. We observed no association with white matter hyperintensities or lacunar infarcts.

Conclusions Presence of cerebral small-vessel disease on brain MRI, particularly cerebral microbleeds, is associated with the severity of diabetic retinopathy.

\section{BACKGROUND}

Compared with healthy individuals, those with type 1 diabetes have an increased risk of circulatory disorders of the brain, such as stroke. ${ }^{1}$ In young individuals with type 1

\section{Significance of this study}

What is already known about this subject?

- Cerebral small-vessel disease is common in neurologically asymptomatic individuals with type 1 diabetes.

- The retinal vasculature is thought to mirror the brain's vasculature.

\section{What are the new findings?}

- Diabetic retinopathy severity is associated with cerebral small-vessel disease in neurologically asymptomatic individuals with type 1 diabetes.

- Of the different manifestations of cerebral smallvessel disease, especially the number of cerebral microbleeds increases with higher Early Treatment Diabetic Retinopathy Study score.

How might these results change the focus of research or clinical practice?

- Further investigations are needed to confirm these associations and their utility in clinical settings.

diabetes, more than half of the cases of stroke are of microvascular etiology, whereas the corresponding number is below $15 \%$ in the general population. ${ }^{2}$ Furthermore, type 1 diabetes is thought to cause organ damage to the central nervous system in similarity with, and in association with, other diabetic organ damage. $^{3}$

Disease of the microvasculature (arterioles, capillaries, and venules) in the central nervous system is termed cerebral small-vessel disease, with the two most common aetiologies being hypertensive vasculopathy and cerebral amyloid angiopathy. Since the vasculature is too microscopic to image in vivo per se, proxies for the disease are evaluated by MRI. Signs of cerebral small-vessel disease on MRI include lacunar infarcts, white matter hyperintensities, cerebral microbleeds (CMBs), and cortical superficial siderosis. ${ }^{45}$ 
In type 1 diabetes, only a few studies have assessed cerebral small-vessel disease more comprehensively, including the above-mentioned manifestations, with brain MRI. ${ }^{6-8}$ We have preciously studied these markers and showed that cerebral small-vessel disease, especially microbleeds, is more common in type 1 diabetes than in the general population. ${ }^{6}$

Whereas cerebral small-vessel disease in vivo can only be studied indirectly by MRI, ${ }^{4}$ the vasculature of the eye is easily visible and can be directly and non-invasively studied by retinal fundus photography. ${ }^{9}$ The retina has often been proposed to act as a window into the brain, reflecting the burden of small-vessel disease, with the hypothesis that disrupted cerebral small vasculature would be mirrored in the retina. ${ }^{1011}$ Retinopathy is prevalent in diabetes, being the most frequent microvascular complication, with retinal changes developing in up to $90 \%$ of individuals with type 1 diabetes, and $40 \%$ of type 2 diabetes. ${ }^{12}{ }^{13}$ In type 2 diabetes, individuals with diabetic retinopathy have a higher prevalence of smallvessel disease markers, white matter hyperintensities, and lacunar infarcts, than subjects without diabetic retinopathy. Furthermore, small-vessel disease severity increases with age and presence of diabetic retinopathy in these individuals. ${ }^{14}$ In the general population, abnormalities of the retinal vasculature have also been linked to cerebral small-vessel disease, especially white matter hyperintensities and lacunar stroke. ${ }^{1015}$

In type 1 diabetes, both cerebral small-vessel disease and diabetic retinopathy are common findings already at a rather young age, in contrast to that observed in the general population or type 2 diabetes. ${ }^{6}{ }^{14}$ Despite this, data on the relationship between cerebral small-vessel disease and diabetic retinopathy in type 1 diabetes are scarce, and studies show contradictory results. ${ }^{61617}$ The association between cerebral small-vessel disease and retinopathy based on fundus images (in contrary to medical records or questionnaires) has been assessed in only one previous study, which found CMBs to be associated with proliferative diabetic retinopathy (PDR). ${ }^{8}$

Furthermore, there are no reports on the association between milder retinopathy than PDR and cerebral small-vessel disease in type 1 diabetes, and thus, it is yet unclear to what extent the overall severity of diabetic retinopathy is associated with microvascular abnormalities of the brain. Hence, we aimed to study the association between diabetic retinopathy assessed by the Early Treatment Diabetic Retinopathy Study (ETDRS) scale, and cerebral small-vessel disease in neurologically asymptomatic individuals with type 1 diabetes.

\section{MATERIALS AND METHODS}

\section{Study participants}

As part of the nationwide Finnish Diabetic Nephropathy (FinnDiane) Study, in 2010 we initiated a substudy at the Helsinki University Hospital study center, with the aim to identify early risk factors for cerebrovascular disease in type 1 diabetes. The FinnDiane Study, ${ }^{18}$ as well as the protocol of the recent substudy, has previously been described in detail. ${ }^{6}$ Inclusion criteria were age $18-50$ years and type 1 diabetes onset $<40$ years. Exclusion criteria were end-stage renal disease, previous clinical signs of cerebrovascular disease, and contraindications for MRI. In 2011-2017, all study participants underwent brain MRI. Of the 191 participants with type 1 diabetes and 30 healthy age-matched and sex-matched controls originally enrolled for the study, we obtained data from fundus images for $189(99 \%)$ and $29(97 \%)$ participants, respectively, all eligible for this study.

The study participants with type 1 diabetes had a median age of 40 (IQR 33-45) years, median duration of diabetes of $21.6(18.2-30.7)$ years, and 101 (53\%) were women. None of the participants had a history of coronary heart disease or peripheral arterial disease.

\section{Methods}

All participants had a thorough evaluation of their medical history, such as diabetic complications, with data verified from participants' medical records. Current medication, anthropometrics, and office blood pressure were recorded, and participants filled in questionnaires on lifestyle, including smoking.

Glycated hemoglobin $\left(\mathrm{HbA}_{1 c}\right)$, creatinine, total cholesterol, low-density lipoprotein-cholesterol, high-density lipoprotein-cholesterol, and triglycerides were determined from blood samples. Glomerular filtration rate was calculated based on the Chronic Kidney Disease Epidemiology Study formula. ${ }^{19}$ Furthermore, 24-hour urine samples were collected for determination of albumin excretion. Albuminuria was defined as urinary albumin excretion rate $\geq 20 \mu \mathrm{g} / \mathrm{min}$ or $\geq 30 \mathrm{mg} / 24$ hours in two out of three urine collections. Blood and urine samples were analyzed in the central laboratory of the Helsinki University Hospital.

Brain MRI was performed with a 3.0 Tesla scanner (Achieva, Philips, Best, The Netherlands) at the Helsinki Medical Imaging Center, Helsinki University Hospital. MRIs were assessed according to standardized criteria ${ }^{520}$ for markers of cerebral small-vessel disease: white matter hyperintensities (a score of $\geq 1$ on the Fazekas scale), CMBs, lacunar infarcts, and superficial siderosis by an experienced neuroradiologist (JM). For each participant, the assessment was repeated three times by the same neuroradiologist, who was blinded to all clinical data except for whether the participant had diabetes. ${ }^{6}$ For analysis, any cerebral small-vessel disease was categorized as presence versus absence of any signs. Furthermore, different manifestations of cerebral small-vessel disease were analyzed separately as categorical variables (eg, presence vs absence of specific manifestation). Participants with CMBs were further categorized based on the number of microbleeds as follows: 0 microbleed, 1-2 microbleeds, and $>2$ microbleeds.

We performed diabetic retinopathy grading based on fundus images, $87 \%$ of which were taken within 1 year 
from the brain MRI. Of the participants with type 1 diabetes, fundus images were available for 179 , and for 10 participants we were able to make reliable evaluations based on the participants' medical records. Fundus images were available for 29 of the controls. Fundus images of both eyes of the participants were evaluated by an experienced ophthalmologist (PS), who was blinded to the clinical data, but not to whether the participant had diabetes or not. Severity of diabetic retinopathy was graded according to the ETDRS severity scale, ${ }^{2122}$ and the grade of the eye presenting more severe diabetic retinopathy was used for the analysis. For those having undergone scatter photocoagulation, the severity of diabetic retinopathy that indicated the treatment was used as the grade, that is, the most severe lifetime diabetic retinopathy. For analysis, participants were categorized based on diabetic retinopathy severity: ETDRS score $\leq 35$ indicating no to mild retinopathy, 43-57 moderate to severe nonPDR (NPDR), and ETDRS score $\geq 61$ representing PDR. Presence of diabetic retinopathy was defined as ETDRS scores $\geq 20$. Diabetic retinopathy severity was analyzed in relation to cerebral small-vessel disease by retinopathy categories as well as by the entire scale.

\section{Statistical analyses}

For analysis of continuous parametric variables, we used the t-test with results presented as mean $\pm \mathrm{SD}$, and for non-parametric variables the Mann-Whitney $\mathrm{U}$ test with results presented as median (IQR). In analysis of ordinal non-parametric variables, we used the Kruskal-Wallis $\mathrm{H}$ test with central tendency presented as median (IQR). To compare categorical variables between groups, we used the $\mathrm{X}^{2}$ test and Fisher's exact test when expected frequencies were $<5$. We used multiple logistic regression to analyze the relationship between cerebral small-vessel disease and diabetic retinopathy. Cerebral small-vessel disease and its different manifestations were analyzed as dependent variables in separate models, with diabetic retinopathy and clinical confounders as independent variables. Results are presented as ORs with 95\% CI. $\mathrm{P}<0.05$ was considered statistically significant. To analyze the conditional probability of the prevalence of cerebral small-vessel disease at a given severity level of diabetic retinopathy, we used positive (PPV) and negative predictive value (NPV) calculations. PPV was calculated as $\mathrm{PPV}=$ number of true positives/number of positive calls, with 'true positives' indicating cases with coinciding diabetic retinopathy and cerebral small-vessel disease and 'positive call' indicating cases with diabetic retinopathy regardless of MRI findings. NPV was calculated as $\mathrm{NPV}=$ number of true negatives/number of negative calls, with 'negative' indicating no retinopathy and 'true negative' neither retinopathy nor cerebral small-vessel disease. Results are presented as percentages with 95\% CI. Analyses were performed with the IBM SPSS Statistics V.22 software (International Business Machines Corporation) and R V.4.0.0.

\section{RESULTS}

Diabetic retinopathy was present in 155 (82\%) of the participants with type 1 diabetes. No to mild diabetic retinopathy (ETDRS score $\leq 35)$ was observed in $137(72 \%)$ participants, moderate to severe NPDR (ETDRS score $43-57)$ in $23(12 \%)$, and PDR (ETDRS score $\geq 61$ ) in $29(15 \%)$ participants. All 29 participants with PDR, 11 $(48 \%)$ with moderate to very severe NPDR, and $4(4 \%)$ with very mild or mild diabetic retinopathy had received laser photocoagulation, altogether 44 participants. Table 1 presents the clinical characteristics of participants with type 1 diabetes based on severity of diabetic retinopathy.

In the participants with type 1 diabetes, cerebral smallvessel disease was observed in $67(35 \%)$, CMBs in 45 (24\%), white matter hyperintensities in $44(23 \%)$, and lacunar infarcts in $4(2 \%)$. Superficial siderosis was not observed in any of the participants. Of the controls, only 3 $(10 \%)$ had cerebral small-vessel disease, and 1 individual $(3 \%)$ had one microaneurysm in one eye (corresponding to an ETDRS score of 20), whereas 28 individuals exhibited no retinopathy-like abnormalities. None of the controls with cerebral small-vessel disease showed any signs of pathologies in the fundus images, and associations between small-vessel disease and retinopathy were, thus, not further analyzed in healthy controls.

Participants with type 1 diabetes and cerebral smallvessel disease had higher ETDRS scores (35 (20-61) vs $20(20-35), \mathrm{p}=0.022)$ and a higher prevalence of PDR ( $25 \%$ vs $9 \%, \mathrm{p}=0.002)$ than those without small-vessel disease. In multivariable logistic regression analysis, PDR was associated with cerebral small-vessel disease (OR 2.57 (95\% CI 1.04 to 6.35)) after adjustment for age, systolic blood pressure, albuminuria, and $\mathrm{HbA}_{1 \mathrm{c}}$. The entire ETDRS scale as a variable, was however, not associated with cerebral small-vessel disease after adjustment for the same confounders.

In the analysis stratified by the presence or absence of diabetic retinopathy (ETDRS $\geq 20$ vs $<20$ ), we observed no association between cerebral small-vessel disease and diabetic retinopathy in those with type 1 diabetes $(\mathrm{p}=0.677)$. Cerebral small-vessel disease was more prevalent $(26(50 \%)$ vs $41(30 \%), \mathrm{p}=0.010)$ in participants with ETDRS score $>35$ compared with those with ETDRS score $\leq 35$. The same was true for ETDRS score $>47$ vs $\leq 47$ $(19(50 \%)$ vs $48(32 \%), \mathrm{p}=0.036)$. When calculating the predictive values of ETDRS $>35$ for cerebral small-vessel disease within the cohort, PPV was 50\% (95\% CI 36\% to $64 \%$ ) and NPV $70 \%$ (62\% to $78 \%$ ).

For the different manifestations of cerebral small-vessel disease, we observed a higher prevalence $(21(40 \%)$ vs 24 $(18 \%), \mathrm{p}=0.001)$ and number $(\mathrm{p}=0.008)$ of $\mathrm{CMBs}$ in those with ETDRS score $>35$ than in those with $\leq 35$. The same was seen for ETDRS score $>47$ compared with ETDRS $\leq 47(15(40 \%)$ vs $30(20 \%), \mathrm{p}=0.011$ and $\mathrm{p}=0.004$, respectively). PPV of ETDRS score $>35$ was $40 \%$ (95\% CI $27 \%$ to $54 \%$ ) and NPV $82 \%$ ( $76 \%$ to $89 \%$ ). No association with 
Table 1 Clinical characteristics of healthy controls and individuals with type 1 diabetes by retinopathy severity

\begin{tabular}{|c|c|c|c|c|c|c|c|}
\hline & $\begin{array}{l}\text { Healthy controls, } \\
\mathrm{N}=29\end{array}$ & $\begin{array}{l}\text { No or mild DR, } \\
\mathrm{N}=137\end{array}$ & P value* & $\begin{array}{l}\text { Moderate to } \\
\text { severe NPDR, } \\
\mathrm{N}=23\end{array}$ & $\mathbf{P}$ valuet & $\begin{array}{l}\text { PDR, } \\
\mathrm{N}=29\end{array}$ & $P$ value $\ddagger$ \\
\hline Female sex, n (\%) & 16 (55.2) & 75 (54.7) & 0.966 & $8(34.8)$ & 0.076 & 17 (58.6) & 0.703 \\
\hline Age, years & 37.7 (31.3-43.4) & $39.8(32.6-44.3)$ & 0.602 & $39.4(34.4-45.6)$ & 0.493 & 41.5 (35.3-47.6) & 0.158 \\
\hline $\begin{array}{l}\text { Diabetes duration, } \\
\text { years }\end{array}$ & - & $20.4(14.4-26.7)$ & - & 22.3 (19.9-29.2) & 0.061 & 35.8 (27.9-37.8) & $<0.001$ \\
\hline BMI, kg/m² & $24.4(22.1-26.1)$ & $25.7(23.6-28.5)$ & 0.032 & $28.9(25.8-31.0)$ & 0.004 & $27.1(23.9-30.1)$ & 0.087 \\
\hline $\begin{array}{l}\text { Systolic blood } \\
\text { pressure, } \mathrm{mm} \text { Hg }\end{array}$ & $121(112-130)$ & $129(118-138)$ & 0.004 & $136(122-144)$ & 0.062 & $132(121-148)$ & 0.195 \\
\hline $\begin{array}{l}\text { Diastolic blood } \\
\text { pressure, } \mathrm{mm} \mathrm{Hg}\end{array}$ & $76(73-85)$ & 77 (70-82) & 0.448 & $81(74-87)$ & 0.035 & $72(74-80)$ & 0.708 \\
\hline $\begin{array}{l}\mathrm{HbA}_{1 \mathrm{c}}, \%(\mathrm{mmol} / \\
\mathrm{mol})\end{array}$ & $\begin{array}{l}5.2(5.0-5.3) \\
(33(31-34))\end{array}$ & $\begin{array}{l}8.0(7.3-8.6) \\
(64(56-71))\end{array}$ & $<0.001$ & $\begin{array}{l}8.1(7.7-8.6) \\
(65(61-70))\end{array}$ & 0.198 & $\begin{array}{l}8.8(7.6-9.7) \\
(73(60-83))\end{array}$ & 0.002 \\
\hline Creatinine, $\mu \mathrm{mol} / \mathrm{L}$ & $74(67-81)$ & $66(61-77)$ & 0.019 & $69(60-79)$ & 0.537 & $77(63-90)$ & 0.009 \\
\hline $\begin{array}{l}\text { Total cholesterol, } \\
\mathrm{mmol} / \mathrm{L}\end{array}$ & $4.6(4.2-5.4)$ & $4.3(4.0-4.9)$ & 0.145 & $4.4(3.8-5.5)$ & 0.649 & $4.8(4.0-5.2)$ & 0.055 \\
\hline $\begin{array}{l}\text { LDL-cholesterol, } \\
\mathrm{mmol} / \mathrm{L}\end{array}$ & $2.6(2.3-3.3)$ & $2.4(2.0-2.8)$ & 0.028 & $2.5(2.0-3.0)$ & 0.714 & $2.4(2.0-3.0)$ & 0.629 \\
\hline $\begin{array}{l}\text { HDL-cholesterol, } \\
\mathrm{mmol} / \mathrm{L}\end{array}$ & $1.45(1.23-1.66)$ & $1.48(1.25-1.82)$ & 0.303 & $1.30(1.15-1.80)$ & 0.153 & $1.56(1.40-1.78)$ & 0.174 \\
\hline $\begin{array}{l}\text { Triglycerides, } \\
\mathrm{mmol} / \mathrm{L}\end{array}$ & $0.84(0.68-1.27)$ & $0.84(0.64-1.21)$ & 0.997 & $1.18(0.88-2.29)$ & 0.003 & $1.01(0.82-1.51)$ & 0.021 \\
\hline $\begin{array}{l}\text { Antihypertensive } \\
\text { medication, n (\%) }\end{array}$ & 0 & $32(23.4)$ & 0.004 & $13(56.5)$ & 0.001 & 22 (75.9) & $<0.001$ \\
\hline $\begin{array}{l}\text { Lipid-lowering } \\
\text { medication, n (\%) }\end{array}$ & 0 & $20(14.6)$ & 0.028 & $11(47.8)$ & $<0.001$ & $10(34.5)$ & 0.011 \\
\hline $\begin{array}{l}\text { Aspirin therapy, } n \\
(\%)\end{array}$ & 0 & $8(5.8)$ & 0.182 & $2(8.7)$ & 0.638 & $4(14.8)$ & 0.226 \\
\hline Albuminuria, n (\%) & 0 & $8(5.8)$ & 0.182 & 9 (39.1) & $<0.001$ & $12(41.4)$ & $<0.001$ \\
\hline $\begin{array}{l}\text { Cerebral small- } \\
\text { vessel disease, } n \\
(\%)\end{array}$ & $3(10.3)$ & 41 (29.9) & 0.030 & 9 (39.1) & 0.378 & 17 (58.6) & 0.003 \\
\hline $\begin{array}{l}\text { White matter } \\
\text { hyperintensities, } \\
\text { n (\%) }\end{array}$ & $2(6.9)$ & $31(22.6)$ & 0.054 & $3(13.0)$ & 0.298 & $10(34.5)$ & 0.179 \\
\hline Microbleeds, n (\%) & $1(3.9)$ & $24(17.5)$ & 0.030 & 8 (34.8) & 0.087 & $13(44.8)$ & 0.001 \\
\hline $\begin{array}{l}\text { Number of } \\
\text { microbleeds }\end{array}$ & $0(0-0)(0-1)$ & $0(0-0)(0-16)$ & 0.053 & $0(0-1)(0-75)$ & 0.035 & $0(0-3)(0-105)$ & $<0.001$ \\
\hline $\begin{array}{l}\text { Lacunar infarcts, } \\
\mathrm{n}(\%)\end{array}$ & 0 & $2(1.5)$ & 0.513 & 0 & $>0.999$ & $2(6.9)$ & 0.141 \\
\hline
\end{tabular}

Data are presented as median (IQR) (maximum-minimum) or number (\%). No or mild DR indicates an Early Treatment Diabetic

Retinopathy Study (ETDRS) score $\leq 35$; moderate to severe NPDR, ETDRS score 43-57; and PDR, ETDRS score $\geq 61$.

*Participants with no or mild DR compared with controls.

†Participants with moderate to severe NPDR compared with no or mild DR, controls excluded.

$\ddagger$ Participants with PDR compared with no or mild DR, controls excluded.

BMI, body mass index; DR, diabetic retinopathy; $\mathrm{HbA}_{1}$, glycated hemoglobin; HDL, high-density lipoprotein; LDL, low-density lipoprotein; NPDR, non-proliferative diabetic retinopathy; PDR, proliferative diabetic retinopathy.

cerebral small-vessel disease emerged for white matter hyperintensities (prevalence $25 \%$ vs $23 \%, \mathrm{p}=0.730$ when ETDRS $>35$ vs $\leq 35 \%$ and $29 \%$ vs $22 \%, p=0.355$ when ETDRS $>47 \mathrm{vs} \leq 47$ ) or for lacunar infarcts (prevalence $4 \%$ vs $2 \%, \mathrm{p}=0.304$ when ETDRS $>35$ vs $\leq 35$, and $5 \%$ vs $1 \%, \mathrm{p}=0.181$ when ETDRS $>47$ vs $\leq 47)$.
In participants with CMBs compared with those without, we observed a higher median ETDRS score (35 (20-65) vs 20 (20-35), $\mathrm{p}=0.024)$ and a higher prevalence of PDR (29\% vs $13 \%, \mathrm{p}=0.002)$. ETDRS scores increased by number of CMBs, and the median score was 20 (IQR: 20-35) in those with $0 \mathrm{CMB}, 20(20-45)$ in those with 1-2 


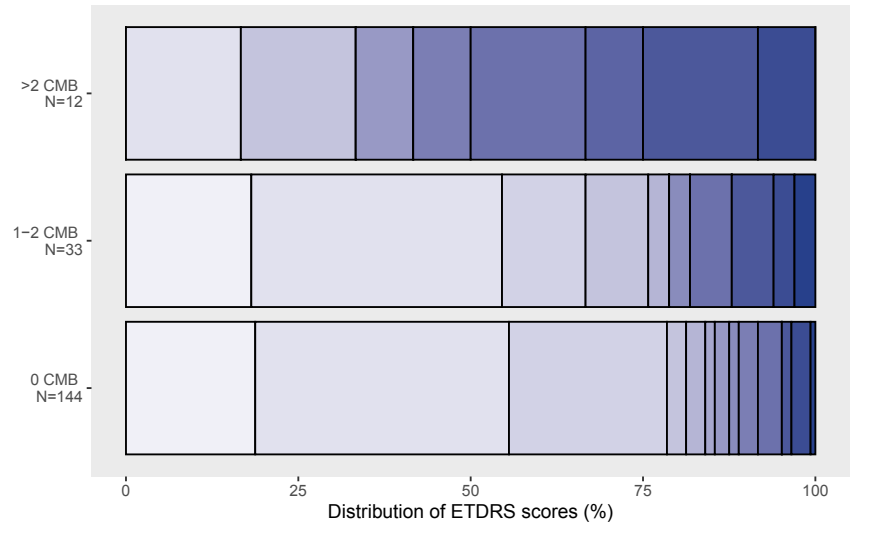

ETDRS score $10 \quad 20$

Figure 1 Stacked bar plot of Early Treatment Diabetic Retinopathy Study (ETDRS) score distribution grouped by number of cerebral microbleeds (CMB).

CMBs, and 63 (43-71) in those with $>2$ CMBs $(p=0.001)$. Figure 1 presents distributions of ETDRS scores by number of microbleeds. An independent association with $>2$ CMBs compared with $\leq 2$ was found for both the ETDRS score (OR 1.05 (95\% CI 1.02 to 1.09)) and PDR (OR 8.52 (95\% CI 1.91 to 37.94)) in separate analyses adjusted for age, systolic blood pressure, albuminuria, and $\mathrm{HbA}_{1 \mathrm{c}}$. When calculating the predictive values of ETDRS $>35$ for the prevalence of $>2$ microbleeds within the cohort, the PPV was $19 \%$ (95\% CI 9\% to 30\%) and the NPV $99 \%$ (97\% to 100\%). The PPV and NPV of PDR were $25 \%$ (95\% CI $8 \%$ to $42 \%$ ) and $96 \%$ (94\% to $99 \%$ ), respectively. No association was observed between the number of white matter hyperintensities and ETDRS score or PDR (data not shown). Due to the low number of cases with lacunar infarcts (four participants), we were not able to study the association between lacunar infarcts and ETDRS score further.

\section{DISCUSSION}

This study shows that cerebral small-vessel disease, particularly microbleeds, is associated with the severity of diabetic retinopathy. The presence of cerebral smallvessel disease was associated with an ETDRS score $\geq 61$ (PDR) after adjustment for confounders. Furthermore, as a novel finding, we found the number of microbleeds to increase with the ETDRS score. This observation could indicate a connection between the severity of asymptomatic cerebrovascular disease and the severity of diabetic retinopathy in type 1 diabetes.

PDR or severe diabetic retinopathy, indicated by laser treatment of the retina, has previously been assessed in relation to markers of cerebral small-vessel disease in type 1 diabetes. ${ }^{816}$ In accordance with our study, CMBs have previously been associated with PDR in a study by Woerdeman et $a l .{ }^{8}$ Moreover, severe diabetic retinopathy has been reported as an independent risk factor for cerebral hemorrhage, as well as for lacunar infarction. ${ }^{16} 17$
Although our study confirmed an association between PDR and the presence of cerebral small-vessel disease (white matter hyperintensities, microbleeds, and/or lacunar infarcts), we did not observe any associations between diabetic retinopathy and white matter hyperintensities or lacunar infarcts in the analyses of the separate manifestations. It is possible that this could be a result of the different manifestations having different etiologies. Indeed, differences in pathological features of cerebral small-vessel disease have previously been described in the general population. ${ }^{4}$ Our negative findings on white matter hyperintensities and lacunar infarcts might also be a result of the relatively low prevalence of these findings, especially lacunar infarcts, in the current cohort, regardless of being a uniquely large cohort of brain MRI in type 1 diabetes.

The association between white matter hyperintensities and diabetic retinopathy has previously been assessed in individuals with type 2 diabetes by Sanahuja et al, who observed an association between cerebral smallvessel disease and diabetic retinopathy, but not between diabetic retinopathy and white matter hyperintensities or lacunar infarctions analyzed separately. ${ }^{14}$ Our observations are in agreement with these findings; however, in contrast to the aforesaid study, our participants were 21 years younger, by the median. Cerebral small-vessel disease has mostly been studied in elderly people without diabetes, and is a condition proposed to relate to ageing, ${ }^{4}$ however, in type 1 diabetes, cerebral small-vessel disease is common already in younger individuals. ${ }^{6}$ In line with our observations, Woerdeman et al also found PDR to be associated with cerebral small-vessel disease in young individuals. However, the association between age and cerebral small-vessel disease was not further elucidated in their study. In our current study, we found PDR to be associated with cerebral small-vessel disease even after adjustment for age, which has not been indicated in previous studies.

As a novel finding, we observed a significant increase in CMBs at a moderate level of diabetic retinopathy severity. We found participants with ETDRS score $>35$, compared with $\leq 35$, to have a higher prevalence and number of CMBs. This could indicate that progression from mild diabetic retinopathy (ETDRS score $\leq 35$ ) is associated with an increased risk of cerebrovascular disease even before new vessel formation (PDR) is manifested. That is, when diabetic retinopathy has progressed from very mild or mild (microaneurysms only or typically additional small hemorrhages), to moderate or more severe retinopathy (more widespread changes in the retina indicated by larger hemorrhages, intraretinal microvascular abnormalities and/or venous beading), it already reflects permanent capillary damage, which correlate with an increased risk of cerebrovascular disease.

Although severe diabetic retinopathy has previously been reported to be independently associated with CMBs and cerebral hemorrhage, ${ }^{816}$ to our knowledge there are no reports on any associations between milder 
diabetic retinopathy and cerebrovascular disease in type 1 diabetes.

In the analyses of the predictive values of the ETDRS score within the cohort, the PPV of ETDRS score $>35$ was low $(19 \%)$ for the prevalence of $>2$ microbleeds. The NPV, however, was high (99\%), indicating that within our cohort, the probability of having $>2$ microbleeds was low when ETDRS score was $\leq 35$. Although a low ETDRS score excluded the presence of multiple microbleeds within the current cohort, the study setting did not allow further analysis of to what extent the ETDRS score could predict CMBs or other manifestations of small-vessel disease in a longitudinal setting.

We have previously showed an association between cerebral small-vessel disease and systolic blood pressure. ${ }^{6} 23$ In the present study, we found the severity of diabetic retinopathy (graded by ETDRS scale) to be significant after adjustment for systolic blood pressure, indicating that, beyond blood pressure, moderate or more severe diabetic retinopathy (ETDRS >35) is independently associated with cerebral small-vessel disease. However, it should be considered that elevated blood pressure and diabetic retinopathy are linked ${ }^{24}$ and due to the crosssectional design of this study, we cannot draw any conclusions about potential causality of the association between diabetic retinopathy and small-vessel disease and their risk factors. As Woerdeman et al previously stated, diabetic retinopathy appears to represent a generalized state of microangiopathy. ${ }^{8}$

The strength of our study is the well-characterized study cohort, age-matched and sex-matched healthy controls, and standardized imaging and assessment of both brain and retinal images. A limitation of our study is the crosssectional study design, which limits the interpretations of causal relationships. To our knowledge, our study is the largest on cerebral small-vessel disease in type 1 diabetes, yet we were not able to do more comprehensive analysis of the burden of cerebral small-vessel disease due to the low number of certain manifestations.

\section{SUMIMARY}

In this study, we conclude that cerebral small-vessel disease is associated with the severity of diabetic retinopathy in type 1 diabetes. Although our results indicate that fundus imaging results could also serve as a means of identifying individuals at greater risk of cerebrovascular complications, further investigations are needed to prove or rule out diabetic retinopathy as a predictor of cerebral small-vessel disease.

\footnotetext{
Author affiliations

${ }^{1}$ Folkhälsan Institute of Genetics, Folkhälsan Research Center, Helsinki, Finland ${ }^{2}$ Department of Nephrology, Helsinki University Central Hospital, Helsinki, Finland ${ }^{3}$ Research Program in Clinical and Molecular Metabolism, University of Helsinki, Helsinki, Finland

${ }^{4}$ Department of Ophthalmology, Helsinki University Central Hospital, Helsinki, Finland

${ }^{5}$ Joslin Diabetes Center, Harvard Medical School, Boston, Massachusetts, USA

${ }^{6}$ Department of Radiology, Karolinska University Hospital, Stockholm, Sweden
}

${ }^{7}$ Department of Radiology, Stanford Medicine, Stanford, California, USA

${ }^{8}$ Department of Neurology, Helsinki University Central Hospital, Helsinki, Finland ${ }^{9}$ Department of Neurology, Sahlgrenska University Hospital, Goteborg, Sweden

${ }^{10}$ Department of Diabetes, Central Clinical School, Monash University, Melbourne, Victoria, Australia

${ }^{11}$ Department of Radiology, Helsinki University Central Hospital, Helsinki, Finland ${ }^{12}$ Department of General Practice and Primary Health Care, University of Helsinki and Helsinki University Hospital, Helsinki, Finland

Acknowledgements We gratefully acknowledge Anna Sandelin, Jaana Tuomikangas, and Mira Korolainen for their skilled technical assistance. We thank Stefan Mutter for help with the statistical analysis. We also thank Pentti Pölönen, Department of Radiology, Helsinki University Hospital, for performing the MRI scans. We are indebted to Professor Markku Kaste, Department of Neurology and Dr Oili Salonen, Department of Radiology, Helsinki University Hospital, for their help in the initiation of the study.

Contributors MIE, PS, DG, CF, SS, RL, TT, JP, P-HG, JM, and LMT contributed to the study design, acquisition of data, as well as the interpretation of data. MIE and LMT had the main responsibility for analyzing the data and writing the first draft of the paper. DG, SS, CF, PS, RL, TT, JP, P-HG, and JM critically revised the manuscript. $\mathrm{P}-\mathrm{HG}$, is the guarantor of this work and, as such, had full access to all the data in the study, and takes responsibility for the integrity of the data and the accuracy of the data analysis.

Funding The study was supported by grants from Folkhälsan Research Foundation, Academy of Finland (275614, 316664, and UAK10121MRI), Wilhelm and Else Stockmann Foundation, Liv och Hälsa Society, Novo Nordisk Foundation (NNF 0C0013659), Sigrid Juselius Foundation, Medical Society of Finland, Päivikki and Sakari Sohlberg Foundation, Finnish Foundation for Cardiovascular Research, EVO governmental grants, University of Helsinki, Diabetes Research Foundation, Diabetes Wellness Finland, Finnish Medical Foundation, Perklén Foundation, Eye Foundation in Finland, and Eye and Tissue Bank Foundation.

Competing interests MIE is a shareholder of BCB Medical Oy. PS has received lecture honoraria from Santen. $T T$ is an advisory board member of Boehringer Ingelheim, Bayer, Bristol Myers Squibb, Lumosa Therapeutics, and Portola Pharma and has received speaker honoraria from the University of Donau (Austria). DG has received lecture or advisory honoraria from AstraZeneca, Boehringer Ingelheim, Fresenius, GE Healthcare, and Novo Nordisk, and support to attend medical meetings from CVRx and Sanofi Aventis. JM has received lecture honoraria from Santen. P-HG. has received lecture honoraria from Astellas, AstraZeneca, Boehringer Ingelheim, Eli Lilly, Elo Water, Genzyme, Medscape, MSD, Mundipharma, Novartis, Novo Nordisk, PeerVoice, Sanofi and Sciarc, and he is an advisory board member of AbbVie, Astellas, AstraZeneca, Bayer, Boehringer Ingelheim, Eli Lilly, Janssen, Medscape, MSD, Mundipharma, Novartis, Novo Nordisk, and Sanofi.

\section{Patient consent for publication Not required.}

Ethics approval The study protocol was carried out in accordance with the Declaration of Helsinki and was approved by the Ethics Committee of Helsinki University Hospital (HUS), ID: HUS/2184/2017 (aiempi 293/13/03/01/2010) and Uusimaa Hospital District. All participants gave their written informed consent.

Provenance and peer review Not commissioned; externally peer reviewed.

Data availability statement Data are available upon reasonable request. The data that support the findings are available from the corresponding author upon reasonable request.

Open access This is an open access article distributed in accordance with the Creative Commons Attribution Non Commercial (CC BY-NC 4.0) license, which permits others to distribute, remix, adapt, build upon this work non-commercially, and license their derivative works on different terms, provided the original work is properly cited, appropriate credit is given, any changes made indicated, and the use is non-commercial. See: http://creativecommons.org/licenses/by-nc/4.0/.

ORCID iD

Marika I Eriksson http://orcid.org/0000-0001-5205-4498

\section{REFERENCES}

1 Janghorbani M, Hu FB, Willett WC, et al. Prospective study of type 1 and type 2 diabetes and risk of stroke subtypes: the nurses' health study. Diabetes Care 2007;30:1730-5.

2 Putaala J, Liebkind R, Gordin D, et al. Diabetes mellitus and ischemic stroke in the young: clinical features and long-term prognosis. Neurology 2011;76:1831-7. 
3 Brands AMA, Kessels RPC, de Haan EHF, et al. Cerebral dysfunction in type 1 diabetes: effects of insulin, vascular risk factors and blood-glucose levels. Eur J Pharmacol 2004;490:159-68.

4 Pantoni L. Cerebral small vessel disease: from pathogenesis and clinical characteristics to therapeutic challenges. Lancet Neurol 2010;9:689-701.

5 Wardlaw JM, Smith EE, Biessels GJ, et al. Neuroimaging standards for research into small vessel disease and its contribution to ageing and neurodegeneration. Lancet Neurol 2013;12:822-38.

6 Thorn LM, Shams S, Gordin D, et al. Clinical and MRI features of cerebral small-vessel disease in type 1 diabetes. Diabetes Care 2019;42:327-30.

7 van Elderen SGC, Brandts A, Westenberg JJM, et al. Aortic stiffness is associated with cardiac function and cerebral small vessel disease in patients with type 1 diabetes mellitus: assessment by magnetic resonance imaging. Eur Radiol 2010;20:1132-8.

8 Woerdeman J, van Duinkerken E, Wattjes MP, et al. Proliferative retinopathy in type 1 diabetes is associated with cerebral microbleeds, which is part of generalized microangiopathy. Diabetes Care 2014;37:1165-8.

9 Abràmoff MD, Garvin MK, Sonka M. Retinal imaging and image analysis. IEEE Rev Biomed Eng 2010;3:169-208.

10 Liew G, Wang JJ, Mitchell P, et al. Retinal vascular imaging: a new tool in microvascular disease research. Circ Cardiovasc Imaging 2008;1:156-61.

11 Wong TY, Klein R, Couper DJ, et al. Retinal microvascular abnormalities and incident stroke: the Atherosclerosis risk in Communities study. Lancet 2001;358:1134-40.

12 Stefánsson E, Bek T, Porta M, et al. Screening and prevention of diabetic blindness. Acta Ophthalmol Scand 2000;78:374-85.

13 Yau JWY, Rogers SL, Kawasaki R, et al. Global prevalence and major risk factors of diabetic retinopathy. Diabetes Care 2012;35:556-64
14 Sanahuja J, Alonso N, Diez J, et al. Increased burden of cerebral small vessel disease in patients with type 2 diabetes and retinopathy. Diabetes Care 2016;39:1614-20.

15 Yatsuya H, Folsom AR, Wong TY, et al. Retinal microvascular abnormalities and risk of lacunar stroke. Stroke 2010;41:1349-55.

16 Hägg S, Thorn LM, Putaala J, et al. Incidence of stroke according to presence of diabetic nephropathy and severe diabetic retinopathy in patients with type 1 diabetes. Diabetes Care 2013;36:4140-6.

17 Hägg S, Thorn LM, Forsblom CM, et al. Different risk factor profiles for ischemic and hemorrhagic stroke in type 1 diabetes mellitus. Stroke 2014;45:2558-62.

18 Thorn LM, Forsblom C, Fagerudd J. Metabolic syndrome in type 1 diabetes. Diabetes Care 2005;28:2019-24.

19 Levey AS, Stevens LA, Schmid CH, et al. A new equation to estimate glomerular filtration rate. Ann Intern Med 2009;150:604-12.

20 Fazekas F, Kleinert R, Roob G, et al. Histopathologic analysis of foci of signal loss on gradient-echo $\mathrm{T}^{*}$-weighted $\mathrm{Mr}$ images in patients with spontaneous intracerebral hemorrhage: evidence of microangiopathy-related microbleeds. AJNR Am J Neuroradiol 1999;20:637.

21 Davis MD, Fisher MR, Gangnon RE, et al. Risk factors for highrisk proliferative diabetic retinopathy and severe visual loss: Early Treatment Diabetic Retinopathy Study Report \#18. Invest Ophthalmol Vis Sci 1998;39:233-52.

22 Grading diabetic retinopathy from stereoscopic color fundus Photographs-An extension of the modified Airlie house classification. Ophthalmology 1991;98:786-806.

23 Eriksson MI, Gordin D, Shams S, et al. Nocturnal blood pressure is associated with cerebral small-vessel disease in type 1 diabetes. Diabetes Care 2020;43:e96-8.

24 Klein R, Klein BE, Moss SE, et al. The Wisconsin epidemiologic study of diabetic retinopathy: XVII. The 14-year incidence and progression of diabetic retinopathy and associated risk factors in type 1 diabetes. Ophthalmology 1998;105:1801-15. 